\title{
Efficacy of Face Masks Used in Uganda: A Laboratory-Based Inquiry during the COVID-19 Pandemic
}

\author{
Gerald Mboowa, ${ }^{1,2}$ Derrick Semugenze, ${ }^{3}$ Hellen Nakabuye, ${ }^{1,3}$ Douglas Bulafu, ${ }^{4}$ and Dickson Aruhomukama ${ }^{1,3 *}$ \\ ${ }^{1}$ Department of Immunology and Molecular Biology, College of Health Sciences, School of Biomedical Sciences, Makerere University, Kampala, \\ Uganda; ${ }^{2}$ The African Center of Excellence in Bioinformatics and Data Intensive Sciences, the Infectious Diseases Institute, Makerere University, \\ Kampala, Uganda; ${ }^{3}$ Department of Medical Microbiology, College of Health Sciences, School of Biomedical Sciences, Makerere University, \\ Kampala, Uganda; ${ }^{4}$ Department of Disease Control and Environmental Health, School of Public Health, College of Health Sciences, Makerere \\ University, Kampala, Uganda
}

\begin{abstract}
With shortages of face masks being reported worldwide, it is critical to consider alternatives to commercially manufactured face masks. This study aimed to test and compare the efficacy of various makes of locally made or homemade cloth face masks obtained from face-mask vendors in Kampala, Uganda, during the COVID-19 pandemic. The testing was performed to assess the bacterial filtration efficiency (BFE), breathability, distance-dependent fitness, and reusability of the locally made or homemade cloth face masks, while considering the most commonly used nonpublished face-mask decontamination approaches in Uganda. During laboratory experimentation, modified protocols from various face-mask testing organizations were adopted. Ten different face-mask types were experimented upon; each face-mask type was tested four times for every single test, except for the decontamination protocols involving washing where KN95 and surgical face masks were not included. Among the locally made or homemade cloth face masks, the double-layered cloth face masks (described as F) had better BFE and distance-dependent fitness characteristics, they could be reused, and had good breathability, than the other locally made or homemade cloth face masks. Despite these good qualities, the certainty of these face masks protecting wearers against COVID-19 remains subject to viral filtration efficiency testing.
\end{abstract}

\section{INTRODUCTION}

The CDC and the WHO endorsed the use of face masks as protective means to check the acquisition and spread of COVID-19. ${ }^{1,2}$ Furthermore, unlike most authorities, the U.S. CDC advised that face masks should also be used by all in public settings as opposed to being used by only the sick. ${ }^{3}$ The protective efficacy of face masks varies, and experimental data concerning the effectiveness of face masks in reducing infections in the community are remarkably insufficient and even contradictory. ${ }^{4-7}$

During this study's conception, global and local shortages of respirators and surgical face masks had been reported by various studies, shortages which were prompting the prolonged use or reuse of respirators and surgical face masks intended for single use $e^{8-11}$. Also, during the same time, the COVID-19 outbreak had sparked an important debate regarding the efficacy of face masks expressly the locally made or homemade cloth face masks. ${ }^{12-16}$ The outbreak also exposed the inadequacy of existing guidelines with regard to the use of locally made or homemade cloth face masks generally used in low- and middle-income countries (LMICs), especially in Africa, where access to the imported commercially manufactured face masks is difficult, majorly because most of the populations cannot afford to acquire these face masks. ${ }^{12-16}$

Also, because of this, most of the populations in LMICs continue to explore non-published approaches to sustain a sufficient supply of face masks, including among others facemask decontamination, which could prolong the wearable life of the face masks beyond their expiration dates and reducing the need to procure more costly respirators, for example, KN95. ${ }^{9}$

\footnotetext{
*Address correspondence to Dickson Aruhomukama, Departments of Immunology and Molecular Biology and Medical Microbiology, College of Health Sciences, School of Biomedical Sciences, Makerere University, P.O. Box 7072, Kampala, Uganda. E-mail: dickson. aruhomukama@chs.mak.ac.ug
}

The labor-intensive and costly decontamination approaches published in several studies, for example, the use of vaporized hydrogen peroxide and ultraviolet germicidal irradiation, exacerbate the predicament for LMICs, promoting most of the populations to continue exploring non-published approaches to sustain a sufficient supply of face masks. ${ }^{8,17-19}$

Also, during this study's conception, Uganda had begun a phased approach of lifting the initially decreed countrywide lockdown. ${ }^{20}$ At the time, the Ugandan government was also reviewing its policy on the mandatory use of face masks in public settings. ${ }^{20}$

Because of this, several untested makes of locally made or homemade cloth face masks, conceivably ineffective to protect wearers against acquiring COVID-19, swamped the Ugandan market, hence making it essential to assess the safety and fitness for use of the several makes of locally made or homemade cloth face masks that were commonly circulating on the Ugandan market during the COVID-19 pandemic.

With the hope of informing the development of policies regarding the use of locally made or homemade cloth face masks to prevent the transmission of COVID-19 in Uganda and other similar LMICs in Africa, this study aimed at testing and comparing the various makes of locally made or homemade cloth face masks obtained from face-mask vendors in Kampala, Uganda, during the COVID-19 pandemic; the testing was performed to assess the bacterial filtration efficiency (BFE), breathability, distance-dependent fitness, and reusability of the locally made or homemade cloth face masks, while considering the most commonly used non-published face-mask decontamination approaches.

\section{MATERIALS AND METHODS}

Study design and sites. This was a laboratory-based descriptive study and was part of a larger study titled: Assessing knowledge, attitudes, perceptions, and skills towards the use 
of face-masks: a community-level perspective (MASKUG2020) that aimed at testing and comparing various materials and forms of cloth face masks procured from face-mask vendors in Kampala, Uganda, during the COVID-19 pandemic. The study was carried out in the Department of Medical Microbiology at the School of Biomedical Sciences, College of Health Sciences, Makerere University, Uganda.

Description and source of the face-masks studied. Ten different types of face masks, each in quadruplicate, were purposively selected and procured from face-mask vendors in Kampala, Uganda's capital (Table 1 and Supplemental Data 6).

Laboratory testing. Four volunteers were engaged in the experiments as described in the Supplemental Files. Appropriately selected, internationally approved standard face masks (KN95) were also included as controls. ${ }^{21}$ Semiquantitative fitness testing for the test and KN95 face masks was performed using a procedure adapted from the $3 \mathrm{M}$ Center for Respiratory Protection (the United States). ${ }^{33}$ The 3M procedure was modified to include the number of squeezes required for the volunteers to taste the saccharin reagent. This procedure was again modified to include testing at 2, 3, 4, 5, and $6 \mathrm{~m}$ to achieve the distance-dependent fit testing as described in Supplemental Data 1 and 2.

Bacterial filtration efficiency of the KN95 and the test face masks was determined using an in-house method where a stream of $0.5 \mathrm{McF}$ arland Mycobacterium smegmatis aerosols was generated using a handheld sprayer and directed through the face masks onto the $7 \mathrm{H} 11$ agar plates using a vacuum pump. All this was performed in a decontaminated biosafety cabinet as described in Supplemental Data 3. The BFE was determined by counting the number of colony-forming units on the test culture plates compared with those on the positive control culture plates. The breathability of the positive control and each type of test face mask was carried out using a procedure adapted from the ASTM E96 (ASTM International, West Conshohocken, PA) desiccant method where anhydrous calcium chloride granules were almost filled in the glass beaker, covered with the face masks, and the difference in weight measured after being left at room temperature. The environmental temperature and humidity of the room were monitored and recorded as described in Supplemental Data 4. In-house reusability was performed for each face-mask type by repeating all the aforementioned procedures after 1) each type of surgical, positive control, and cloth face masks were sprayed with $70 \%$ ethanol and dried under the sun; 2) each cloth face-mask type was washed with a nonbacterial soap and dried under the sun; and 3) each cloth facemask type was washed with a nonbacterial soap, dried under the sun, and ironed as described in Supplemental Data 5.

Data management and analysis. Data from the laboratory collection forms previously validated by the study principal investigators and the laboratory team were entered, cleaned, and analyzed using Microsoft Excel 2016 (Microsoft Corporation, Redmond, WA) and STATA 14.0 statistical software (StataCorp, College Station, TX).

1. Bacterial filtration efficiency of the face masks tested. This was calculated using the formula:

$=\frac{\text { Positive control (cfu) }- \text { Mean Test plate }(\mathrm{cfu})}{\text { Positive control (cfu) }} \times 100=$ BFE, to identify the \% microorganisms that had penetrated through each mask material and results presented in Table 1. The mean and SD of the masks at each treatment method were calculated in STATA 14.0 (StataCorp) and presented in Table 1.

2. In-house breathability testing of the face masks. To determine the average weight increase, the increase in the weight of the beakers in each of the experiments was added and divided by the number of experiments performed as per the formula below:

$(w t 1+w t 2+w t 3+w t 4) / 4=$ Average weight increase.

The average weight increase was then plotted as shown in Figure $1 \mathrm{~B}$, in the following text, to identify the mask with the highest breathability.

TABLE 1

Bacterial filtration efficiency of the face masks

\begin{tabular}{|c|c|c|c|c|c|c|}
\hline \multirow[b]{2}{*}{ Type/description of face mask } & \multicolumn{3}{|c|}{ Mask BFE (\%) } & \multirow[b]{2}{*}{$\begin{array}{l}\text { Washed, dried, } \\
\text { and ironed }\end{array}$} & \multirow[b]{2}{*}{$\begin{array}{l}\mathrm{NDA}^{*} \\
\text { approved }\end{array}$} & \multirow[b]{2}{*}{$\begin{array}{c}\text { GOU† } \\
\text { approved }\end{array}$} \\
\hline & $\begin{array}{c}\text { No } \\
\text { decontamination }\end{array}$ & $70 \%$ ethanol & $\begin{array}{l}\text { Washed and dried } \\
\text { under the sun }\end{array}$ & & & \\
\hline $\begin{array}{l}\text { A- Single-layer polypropylene with elastic } \\
\text { straps }\end{array}$ & $\geq 99.9$ & $\geq 99.9$ & $\geq 99.9$ & - & No & No \\
\hline $\begin{array}{l}\text { B- Single-layer thick material with thick } \\
\text { elastic straps }\end{array}$ & $\geq 99.9$ & $\geq 99.9$ & $\geq 99.9$ & $\geq 99.9$ & No & No \\
\hline $\begin{array}{l}\text { C- Single-layer thick material with single } \\
\text { elastic straps }\end{array}$ & $\geq 99.9$ & $\geq 99.9$ & $\geq 99.9$ & $\geq 99.9$ & No & No \\
\hline $\begin{array}{l}\text { D- Double-layered with kitengi on the } \\
\text { outside, and cotton on the inside }\end{array}$ & $\geq 99.9$ & $\geq 99.9$ & $\geq 99.9$ & $\geq 99.9$ & No & No \\
\hline $\begin{array}{l}\text { E- Single-layer kitengi with elastic straps } \\
\text { for attaching around ears }\end{array}$ & $\geq 99.9$ & $\geq 99.9$ & $\geq 99.9$ & $\geq 99.9$ & No & No \\
\hline $\begin{array}{l}\text { F- Double-layered cloth nonelastic straps } \\
\text { for tying around the head }\end{array}$ & $\geq 99.9$ & $\geq 99.9$ & $\geq 99.9$ & $\geq 99.9$ & No & No \\
\hline $\begin{array}{l}\text { G- Surgical mask bought from a } \\
\text { pharmacy }\end{array}$ & $\geq 99.9$ & $\geq 99.9$ & - & - & Yes & Yes \\
\hline H- Surgical mask bought from street & $\geq 99.9$ & $\geq 99.9$ & - & - & No & No \\
\hline $\begin{array}{l}\text { I- Face scrub cloth with elastic straps for } \\
\text { attaching around ears }\end{array}$ & $\geq 99.9$ & $\geq 99.9$ & $\geq 99.9$ & $\geq 99.9$ & No & No \\
\hline $\begin{array}{l}\text { J-Thick material with a single elastic strap } \\
\text { for tying around the head }\end{array}$ & $\geq 99.9$ & $\geq 99.9$ & $\geq 99.9$ & $\geq 99.9$ & No & No \\
\hline K- KN95 face mask & $\geq 99.9$ & $\geq 99.9$ & - & - & Yes & Yes \\
\hline Mean (SD) & $\geq 99.9( \pm 0.0)$ & $\geq 99.9( \pm 0.0)$ & $\geq 99.9( \pm 0.0)$ & $\geq 99.9( \pm 0.0)$ & - & - \\
\hline
\end{tabular}

*Uganda National Drug Authority.

† Government of Uganda. 
3. Distance-dependent fitness testing of the face masks. Data on distance-dependent fitness was analyzed in Excel, where it was described and presented as graphs as shown in Figure 2.

Ethics approval and consent to participate. Ethical approvals were obtained from the ${ }^{1}$ School of Biomedical Sciences-Research and Ethics Committee, College of Health Sciences, Makerere University (approval number: SBS-793), and the Uganda National Council for Science and Technology (approval number: SS489ES). Written informed consent was obtained from each of the study volunteers before performing the laboratory investigations.

\section{RESULTS}

Bacterial filtration efficiency of the face masks tested. All the face masks that had been tested had a BFE of $\geq 99.9 \%$, regardless of the face-mask decontamination method used (Table 1).

In-house breathability testing of the face-masks. There was a significant increase in the average weight of the beakers containing desiccant and sealed with face masks A-J after the 24-hour duration of the testing. Notably, the glass beakers containing the desiccant that had been sealed with the facemask $\mathrm{H}$ had a significantly higher mean weight gain than the other face masks, whereas face-mask $F$ had a significantly higher mean weight gain than the other face masks tested, regardless of the face-mask decontamination method used (Figure 1).

Distance-dependent fitness testing of the face masks. Figure 2 shows the relationship between the average number of sprays to tasting saccharin with distance, as the measure for distance-dependent fitness testing of the face masks.

Face-mask testing without decontamination. At $1 \mathrm{~m}$, the study volunteers wearing face-masks A, B, C, D, E, F, G, H, I, and $\mathrm{J}$ tasted saccharin after an average of $17,6,40,17,9,11$, $10,5,33$, and 11 sprays, respectively. The average number of sprays required to taste saccharin then increased with an increase in the distance. The average number of sprays until saccharin was tasted for face-masks $G$ and $H$ increased exponentially to $\geq 500$ at $2 \mathrm{~m}$, whereas that for face-mask $\mathrm{F}$ increased steadily to $2 \mathrm{~m}$ at which point they increased exponentially, surpassing the 500-spray mark at $3 \mathrm{~m}$. Also, the average number of sprays until saccharin was tasted for facemask $\mathrm{J}$ increased steadily to $5 \mathrm{~m}$ at which point they surpassed the 500-spray mark, whereas that for the face-masks $\mathrm{A}, \mathrm{B}, \mathrm{C}, \mathrm{D}, \mathrm{E}$, and I increased steadily to $6 \mathrm{~m}$ but did not surpass the 500-spray mark. So, face-masks $G$ and $H$ passed the distance-dependent test at $2 \mathrm{~m}$, whereas mask $\mathrm{F}$ and $\mathrm{J}$ passed the same test at 3 and $6 \mathrm{~m}$, respectively. All single-layered face masks did not pass for a distance-dependent fitness test. Furthermore, with the KN95 face mask, saccharin was not tasted at any distance after up to 500 sprays, thus not including its findings in the figure (Figure 2A).

Face-mask testing after decontamination with $70 \%$ ethanol. At $1 \mathrm{~m}$, the study volunteers wearing face-masks $A$, $\mathrm{B}, \mathrm{C}, \mathrm{D}, \mathrm{E}, \mathrm{F}, \mathrm{G}, \mathrm{H}, \mathrm{I}$, and $\mathrm{J}$ tasted saccharin after an average of $4,6,5,6,4,11,5,4,8$, and 11 sprays, respectively. However, the average number of sprays required to taste saccharin then increased with an increase in the distance. The average number of sprays until saccharin was tasted for face-mask $F$ increased steadily to $2 \mathrm{~m}$ at which point they increased exponentially surpassing the 500 -spray mark at $3 \mathrm{~m}$, whereas those of face-mask I increased steadily to $5 \mathrm{~m}$ at which point they then increased exponentially also surpassing the 500 spray-mark at $6 \mathrm{~m}$. Therefore, on decontamination with $70 \%$, face-masks $F$ and I passed the distance-dependent fitness test. Noteworthy, the face-masks $\mathrm{G}$ and $\mathrm{H}$ failed the distancedependent fitness test. Furthermore, with the KN95 face mask, saccharin was not tasted at any distance after up to 500 sprays, thus not including its findings in the figure (Figure 2B).

Face-mask testing after washing of face masks with a nonbacterial soap and drying them under the sun. At $1 \mathrm{~m}$, the study volunteers wearing face-masks $A, B, C, D, E, F, I$, and $\mathrm{J}$ tasted saccharin after an average of $3,4,2,7,5,6,6$, and 4 sprays, respectively. However, the average number of sprays required to taste saccharin then increased with an increase in the distance. The average number of sprays until saccharin was tasted for face-mask $\mathrm{F}$ increased steadily to $3 \mathrm{~m}$ at which point they increased exponentially till they surpassed the 500 spray-mark at $4 \mathrm{~m}$, whereas for face-mask I, they increased to

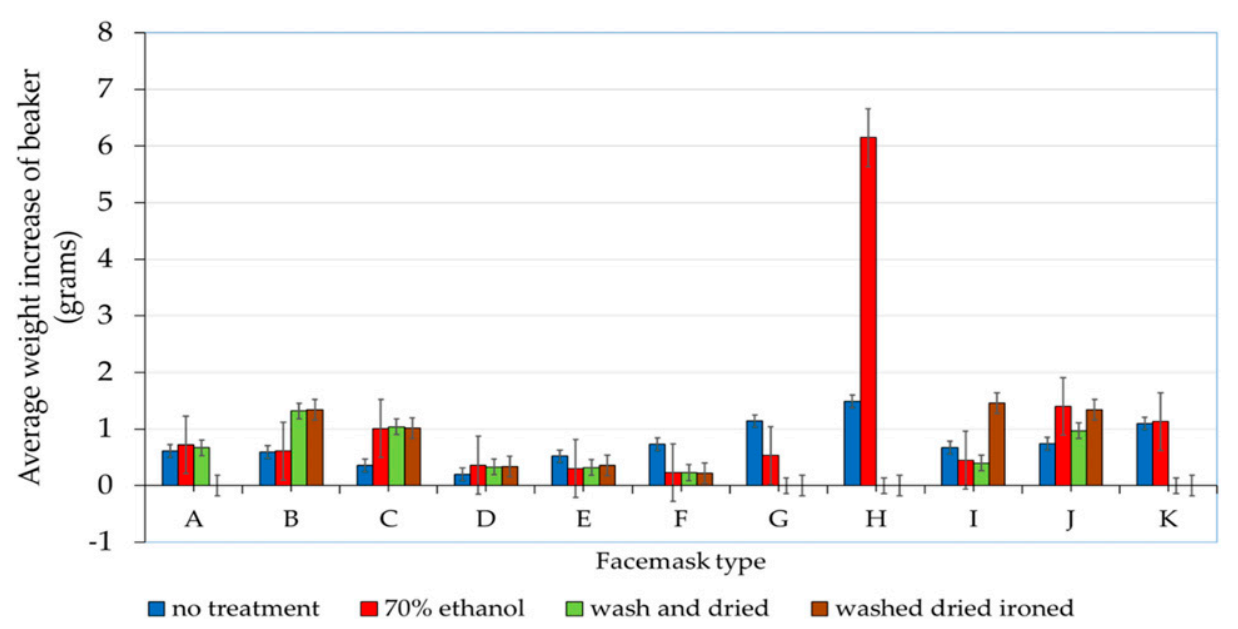

FIGURE 1. Average increase in weight of beakers containing the desiccant sealed with the face masks (A-J), when not treated (blue), after treatment with $70 \%$ ethanol (red), washing and drying (green), and washing, drying, and ironing (maroon). The error bars represent the SD of the data sets. This figure appears in color at www.ajtmh.org. 
A No decontamination

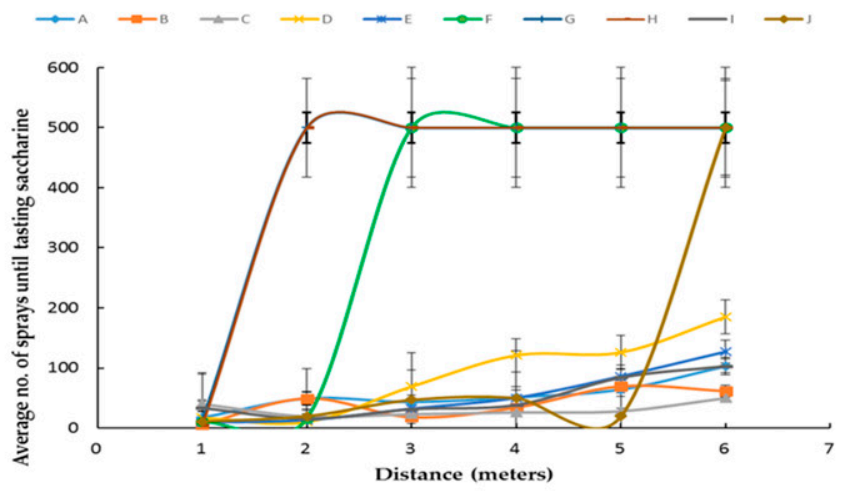

C Washing with non-bacterial soap and drying under the sun

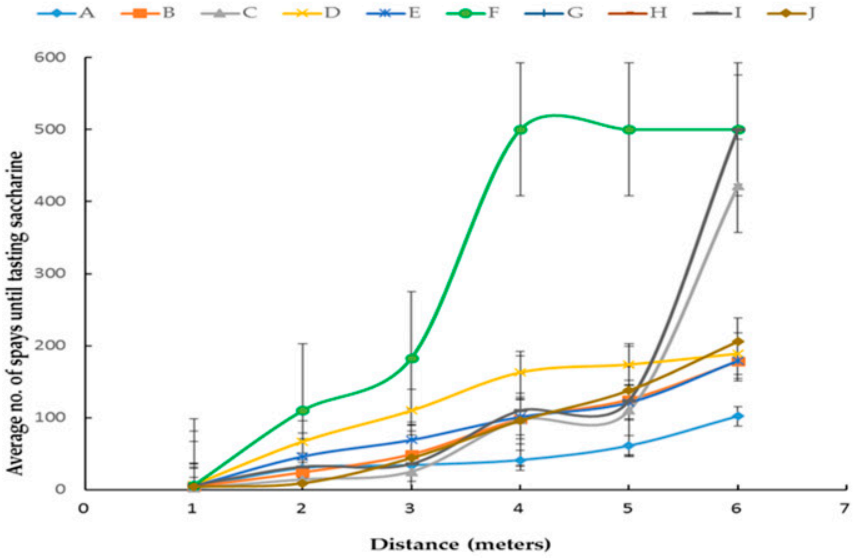

B Treatment with $70 \%$ ethanol

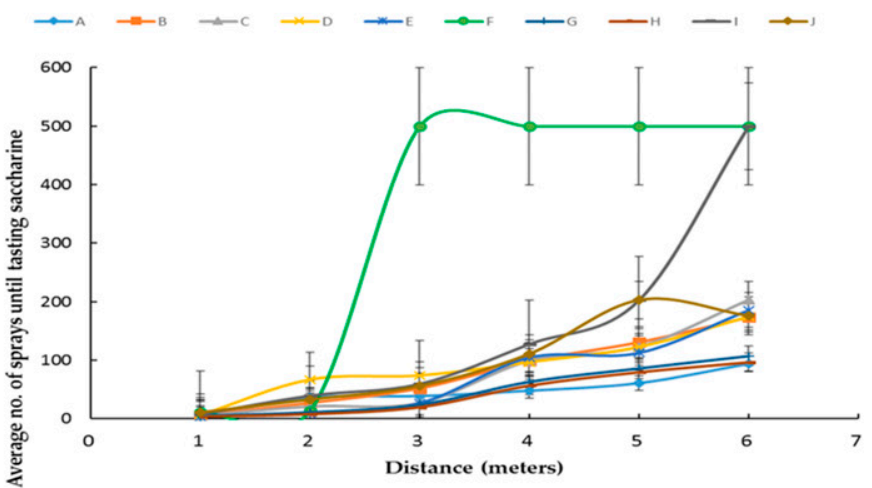

D Washing with non-bacterial soap, sun drying, and ironing

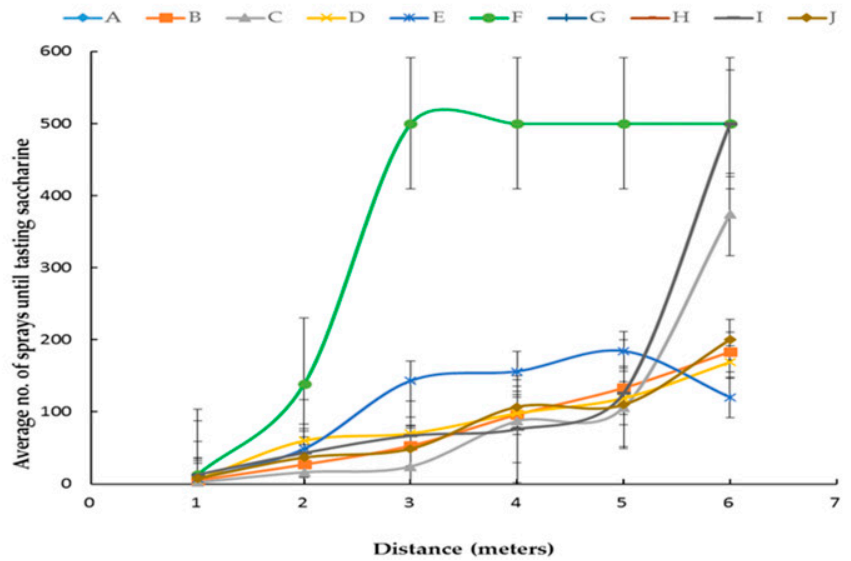

FIGURE 2. Distance-dependent fitness testing of the face masks with different treatment measures. Trends of the sensitivity of saccharin solution with the increase in distance from the participants (volunteers) wearing face masks, without treatment (A), after decontamination with $70 \%$ ethanol (B), after washing the face masks with a nonbacterial soap and drying them under the sun (C), and after washing the face masks with a nonbacterial soap, drying them under the sun, and ironing them (D). The error bars represent the SD of the data sets. This figure appears in color at www.ajtmh.org.

$5 \mathrm{~m}$ at which point they then increased exponentially surpassing the 500 spray-mark at $6 \mathrm{~m}$. Therefore, on washing the face masks with a nonbacterial soap and drying them under the sun, mask $F$ and mask I passed the distance-dependent fitness test. The KN95 face mask could not be used in this set of experiments, and hence the absence of its findings in the figure (Figure 2C).

Face-mask testing after washing of face masks with a nonbacterial soap, drying them under the sun, and ironing them. At $1 \mathrm{~m}$, the study volunteers wearing face-masks $A, B$, C, D, E, F, I, and J required an average of 5, 2, 6, 7, 13, 13, and 8 sprays, respectively. However, the average number of sprays required to taste saccharin then increased with an increase in the distance. The average number of sprays until saccharin was tasted for face-mask $F$ increased steadily to $2 \mathrm{~m}$ at which point they increased exponentially surpassing the 500 spraymark at $3 \mathrm{~m}$, whereas for face-mask I, they increased steadily to $5 \mathrm{~m}$ at which point they increased exponentially surpassing the 500 spray-mark at $6 \mathrm{~m}$. Therefore, on washing the face masks with a nonbacterial soap, drying them under the sun, and ironing, face-masks $F$ and I passed the distancedependent fitness test. The KN95 face mask could not be used in this set of experiments, and hence the absence of its findings in the figure (Figure 2D).

\section{DISCUSSION}

To the best of our understanding, this is the initial study assessing the efficacy of homemade cloth face masks in Uganda. We found that locally produced double-layered cloth face masks have properties suggesting appropriate protection against SARS-CoV-2 transmission, potentially allowing use of these masks, rather than more expensive surgical face masks or respirators, to help control COVID-19 in LMICs.

This study's finding where surgical face masks obtained from the community pharmacy or street vendors had sufficient BFE and more reliable breathability than any other type of locally made or homemade cloth face masks that had been tested is consonant with the findings of related studies. ${ }^{22-24}$ These studies alluded to the effectiveness of surgical face masks in offering protection against infectious aerosols, for example, SARS-CoV-2, attributing this to their excellent qualities of BFE and breathability. This finding is contradictory with those of other studies. ${ }^{25-27}$ These studies stated inefficiencies in BFE of surgical face masks, inefficiencies which likely negatively affect the ability of these face masks to offer protection against infectious aerosols. However, various observational studies have found no notable advantages of other respirators, for example, KN95 over surgical face masks. They 
have also indicated the ability of these face masks to not only offer protection against infectious aerosols like SARS-CoV-2 but also offer a cheaper alternative to the other respirators, for example, KN95, which have been reported to offer better protection than the surgical face masks. ${ }^{9,22,28-30}$ Therefore, notwithstanding the shortcomings of surgical face masks, there remains a reason for optimism concerning their realworld effectiveness.

The variances in performance of the surgical face masks that had been obtained from the community pharmacy and the street vendors reported in this study could have been due to the different materials and/or the make of these face masks. This thinking has also been documented in a related study. ${ }^{31}$ In this study, surgical face masks by different manufacturers were reported to provide diverse levels of protection to wearers.

The findings of this study that point toward decontamination of surgical face masks obtained from the street vendors using $70 \%$ ethanol, likely negatively affecting the general efficacy of these face masks, could have been due to the $70 \%$ ethanol damaging not only the structural integrity of the surgical face masks but also other characteristics of the face masks, for example, the hydrophobicity, a thought that has also been shared in related studies. ${ }^{11,21,32}$

The findings of this study in which locally made or homemade, double-layered cloth face masks were found to have good breathability, BFE, and the potential to be reused following several non-published decontamination approaches could be related to those of related studies, ${ }^{5,33}$ in which face masks that had been made from two layers of quilt fabric with household paper towels as filters were reported to be viable alternatives to surgical face masks and other respirators such as KN95 and N95. Although these studies recognized the supremacy of surgical face masks over cloth face masks, they highlighted that the use of a cloth face mask was several-fold more effective than not wearing a face mask at all.

As the world, in particular LMICs standing to benefit the most, ${ }^{18}$ seek ways of prolonging the wearable life of face masks and reducing the need to procure more costly respirators, this study identified locally made or homemade, doublelayered cloth face masks with reusable potential, following different non-published but commonly used decontamination approaches. Also, similar to the findings of related studies, ${ }^{34,35}$ this study informs local mass production of cloth face masks, by small-scale enterprises using low-cost and locally available resources to ensure the widest availability and use of face masks to prevent the acquisition and spread of COVID-19.

Our study had some limitations. First, the study used $M$. smegmatis as a pathogen in the BFE testing; this organism is 3- to 5- $\mu \mathrm{m}$ long, whereas the recommended Staphylococcus aureus is 0.5- to 1.5- $\mu \mathrm{m}$ long, and the SARS-CoV-2 virion is 50 - to $200-\mathrm{nm}$ long. Second, the study was unable to pursue viral filtration efficiency (VFE) testing. Hence, it is uncertain whether results based on $M$. smegmatis are relevant for protection against viral pathogens. Third, automated aerosol generation was not possible, and so this study used handheld sprayers for aerosols. Fourth, although we measured temperature and humidity during assays, the wind speed was not measured, and this may have affected aerosol transmission.

The study identified locally made or homemade doublelayered cloth face masks (face masks described as F) that had good breathability, BFE, and could be reused, in attempts to protect against infectious aerosols of SARS-CoV-2. Further advancements in the design of such face masks to resemble surgical and KN95 face masks and testing including VFE could inform the reliability of the use of these face masks in protecting wearers against COVID-19. These face masks could also serve as cheaper alternatives for populations in lowincome settings where access to surgical face masks and other respirators such as KN95 is limited.

Received January 9, 2021. Accepted for publication March 5, 2021.

Published online March 16, 2021.

Note: Supplemental data appear at www.ajtmh.org.

Acknowledgments: We thank Okello Isaac Opio, Sserubiri James, Kaddu Arafat, and Musanje Isaac who volunteered for the laboratory testing, and Nagawa Bridget Tamale from Elevate Research Services, who helped in data analysis. The American Society of Tropical Medicine and Hygiene has waived the Open Access fee for this article due to the ongoing COVID-19 pandemic and has assisted with publication expenses.

Financial support: This work was supported by the government of Uganda through Makerere University Research and Innovations Fund (RIF) under the RIF Special COVID-19 Research and Innovation Awards-2020 (Grant \#: MAK/DVCFA/151/20).

Disclaimer: The views expressed herein are those of the author(s) and not necessarily those of the government of Uganda and Makerere University Research and Innovations Fund.

Authors' addresses: Gerald Mboowa, Department of Immunology and Molecular Biology, College of Health Sciences, School of Biomedical Sciences, Makerere University, Kampala, Uganda, and The African Center of Excellence in Bioinformatics and Data Intensive Sciences, the Infectious Diseases Institute, Makerere University, Kampala, Uganda, E-mail: gerald.mboowa@chs.mak.ac.ug. Derrick Semugenze, Department of Medical Microbiology, College of Health Sciences, School of Biomedical Sciences, Makerere University, Kampala, Uganda, E-mail: dsemugenze@gmail.com. Hellen Nakabuye and Dickson Aruhomukama, Department of Immunology and Molecular Biology, College of Health Sciences, School of Biomedical Sciences, Makerere University, Kampala, Uganda, and Department of Medical Microbiology, College of Health Sciences, School of Biomedical Sciences, Makerere University, Kampala, Uganda, E-mails: joellahellen@gmail.com and dickson.aruhomukama@chs.mak.ac.ug. Douglas Bulafu, Department of Disease Control and Environmental Health, School of Public Health, College of Health Sciences, Makerere University, Kampala, Uganda, E-mail: bulafudouglas@gmail.com.

This is an open-access article distributed under the terms of the Creative Commons Attribution (CC-BY) License, which permits unrestricted use, distribution, and reproduction in any medium, provided the original author and source are credited.

\section{REFERENCES}

1. WHO, 2020. Infection Prevention and Control during Health Care when Novel Coronavirus (nCoV) Infection Is Suspected: Interim Guidance, 25 January 2020. Geneva, Switzerland: World Health Organization.

2. Maclntyre $C R$, Chughtai $A A, 2020$. A rapid systematic review of the efficacy of face masks and respirators against coronaviruses and other respiratory transmissible viruses for the community, healthcare workers and sick patients. Int J Nurs Stud 108: 103629.

3. Chughtai AA, Seale H, Islam MS, Owais M, Macintyre CR, 2020. Policies on the use of respiratory protection for hospital health workers to protect from coronavirus disease (COVID-19). Int $J$ Nurs Stud 105: 103567.

4. Dhillon RS, Karan A, Beier D, Srikrishna D, 2020. We Need Better Masks. Available at: https://hbr.org/2020/06/we-need-bettermasks. Accessed June 26, 2020. 
5. Javid B, Weekes MP, Matheson NJ, 2020. COVID-19: Should the Public Wear Face Masks? British Medical Journal Publishing Group. Available at: https://scholar.google.com/scholar?hl=en $\% 26$ as_sdt $=0 \% 2 \mathrm{C} 5 \% 26 \mathrm{q}=\mathrm{Javid}+\mathrm{B} \% 2 \mathrm{C}+$ Weekes+MP\%2C+ Matheson+NJ\%2C+2020.+COVID-19\%3A+Should+the+Public+ Wear+Face+Masks3F+British+Medical+Joumal+Publishing+Group. $\% 26 b t n G=$.

6. Lee KP, Yip J, Kan CW, Chiou JC, Yung KF, 2020. Reusable face masks as alternative for disposable medical masks: factors that affect their wear-comfort. Int J Environ Res Public Health 17: 6623.

7. Feng S, Shen C, Xia N, Song W, Fan M, Cowling BJ, 2020. Rational use of face masks in the COVID-19 pandemic. Lancet Respir Med 8: 434-436.

8. Toomey $\mathrm{E}$ et al., 2020. Extended use or re-use of single-use surgical masks and filtering facepiece respirators during COVID-19: a rapid systematic review. Infection Control \& Hospital Epidemiology, 1-25.

9. Dugdale CM, Walensky RP, 2020. Filtration efficiency, effectiveness, and availability of N95 face masks for COVID-19 prevention. JAMA Intern Med. 180: 1612-1613.

10. Coia JE et al., 2013. Guidance on the use of respiratory and facial protection equipment. $J$ Hosp Infect 85: 170-182.

11. Rubio-Romero JC, del Carmen Pardo-Ferreira M, García JAT, Calero-Castro S, 2020. Disposable masks: disinfection and sterilization for reuse, and non-certified manufacturing, in the face of shortages during the COVID-19 pandemic. Saf Sci 129: 104830.

12. Chughtai AA, Seale H, Maclntyre CR, 2013. Availability, consistency and evidence-base of policies and guidelines on the use of mask and respirator to protect hospital health care workers: a global analysis. BMC Res Notes 6: 216.

13. Martin GP, Hanna E, McCartney M, Dingwall R, 2020. Science, society, and policy in the face of uncertainty: reflections on the debate around face coverings for the public during COVID-19. Crit Public Health 30: 501-508.

14. Lyu W, Wehby GL, 2020. Community use of face masks and COVID-19: evidence from A Natural Experiment of State Mandates in the US: study examines impact on COVID-19 growth rates associated with state government mandates requiring face mask use in public. Health Aff 39: 1419-1425.

15. Cheng KK, Lam TH, Leung CC, 2020. Wearing face masks in the community during the COVID-19 pandemic: altruism and solidarity. Lancet.

16. Chughtai AA, Seale H, Macintyre CR, 2020. Effectiveness of cloth masks for protection against Severe acute respiratory Syndrome coronavirus 2. Emerg Infect Dis 26: e200948.

17. Rodriguez-Martinez CE, Sossa-Briceño MP, Cortés-Luna JA, 2020. Decontamination and reuse of N95 filtering facemask respirators: a systematic review of the literature. Am J Infect Control 48: 1520-1532.

18. Li DF, Cadnum JL, Redmond SN, Jones LD, Donskey CJ, 2020. It's not the heat, it's the humidity: effectiveness of a rice cookersteamer for decontamination of cloth and surgical face masks and N95 respirators. Am J Infect Control 48: 854-855.

19. Ma Q, Shan H, Zhang C, Zhang H, Li G, Yang R, Chen JM, 2020. Decontamination of face masks with steam for mask reuse in fighting the pandemic COVID-19: experimental supports. J Med Virol 92: 1971-1974.

20. Uganda Ministry of Health. Available at: https://www.health. go.ug/covid/wp-content/uploads/2020/05/FINAL-GUIDELINESON-MASK-USE-1-1.pdf. Accessed on May 8, 2020.

21. Chua MH et al., 2020. Face masks in the new COVID-19 normal: materials, testing, and perspectives. Research 2020: 7286735.

22. Johnson DF, Druce JD, Birch C, Grayson ML, 2009. A quantitative assessment of the efficacy of surgical and N95 masks to filter influenza virus in patients with acute influenza infection. Clin Infect Dis 49: 275-277.

23. Ang B, Poh BF, Win MK, Chow A, 2010. Surgical masks for protection of health care personnel against pandemic novel swineorigin influenza $A(\mathrm{H} 1 \mathrm{~N} 1)-2009$ : results from an observational study. Clin Infect Dis 50: 1011-1014.

24. LiY, Wong T, Chung J, Guo YP, Hu JY, Guan YT, Guan YT, Yao JY, Song QW, Newton E, 2006. In vivo protective performance of N95 respirator and surgical facemask. Am J Ind Med 49: 1056-1065.

25. Booth CM, Clayton M, Crook B, Gawn JM, 2013. Effectiveness of surgical masks against influenza bioaerosols. J Hosp Infect 84: 22-26.

26. Checchi L, Montevecchi M, Moreschi A, Graziosi F, Taddei P, Violante FS, 2005. Efficacy of three face masks in preventing inhalation of airborne contaminants in dental practice. J Am Dent Assoc 136: 877-882.

27. Bae $S$ et al., 2020. Effectiveness of surgical and cotton masks in blocking SARS-CoV-2: a controlled comparison in 4 patients. Ann Intern Med 173: W22-W23.

28. Bischoff WE, Reid T, Russell GB, Peters TR, 2011. Transocular entry of seasonal influenza-attenuated virus aerosols and the efficacy of N95 respirators, surgical masks, and eye protection in humans. J Infect Dis 204: 193-199.

29. Oberg T, Brosseau LM, 2008. Surgical mask filter and fit performance. Am J Infect Control 36: 276-282.

30. Benson SM, Novak DA, Ogg MJ, 2013. Proper use of surgical N95 respirators and surgical masks in the OR. AORN J 97: 457-470.

31. Wen Z, Chen J, Zhao J, Wang J, Lu J, Li J, 2007. Evaluation of the efficacy of surgical mask in filtering bacterial aerosol [J]. Chin $\mathrm{J}$ Disinfect 4.

32. Smith JS et al., 2020. Effect of various decontamination procedures on disposable N95 mask integrity and SARS-CoV-2 infectivity. J Clin Trans/ Sci 1-14.

33. Teesing GR, van Straten B, de Man P, Horeman T, 2020. Is there an adequate alternative for commercially manufactured face masks? A comparison of various materials and forms. $J$ Hosp Infect 106: 246-253.

34. Dargaville T, Spann K, Celina M, 2020. Opinion to address a potential personal protective equipment shortage in the global community during the COVID-19 outbreak. Polym Degrad Stab 176: 109162.

35. Missoni E, Armocida B, Formenti B, 2020. Face masks for all and all for face masks in the COVID-19 pandemic: community level production to face the global shortage and shorten the epidemic. Disaster Med Public Health Prep 1-5. 